\title{
Hastane öncesi alanda ve hastane acil servislerinde çalışan sağlık ekibinin etik duyarlılıklarının belirlenmesi
}

\author{
Secil Taylan', Sevban Arslan² \\ ${ }^{1}$ Çukurova Üniversitesi Sağlık Hizmetleri Meslek Yüksekokulu- Adana \\ 2 Çukurova Universitesi Sağlık Bilimleri Fakültesi, Hemşirelik Bölümü, Adana
}

Öz

Amaç: Hastane öncesi alanda ve hastane acil servislerinde çalışan sağlık ekibinin etik duyarlılıklarını ve etkileyen faktörleri incelemektir. Yöntem: Tanımlayıcı olarak planlanan araştırmanın evrenini Adana il sınırları içindeki üniversite ve devlet hastanelerinin acil servisleri ve Adana İl Sağlık Müdürlüğü ambulans istasyonlarında çalışan sağlık ekibi oluşturmaktadır. Araştırma verileri "Bireysel Bilgi Formu" ve "Ahlaki Duyarlılık Anketi" kullanılarak elde edildi. Bulgular: Araştırmada sağlık çalışanlarının \%68.7'sinin kadın, \%45.3'inin evli, \%54.7'sinin bekâr olduğu, \%64.0'ının çocuk sahibi olmadığı; \%82.3'ünün mesleğini kendisinin tercih ettiği, \%89.1'inin mesleğini severek yaptığı, \%79.8'inin etik eğitimi aldığı, \%86.6'sının etikle ilgili bir yayın takip etmediği, \%71.4'ünün çalıştığı kurumda etik kurul olmadığı saptanmıştır. Sağlık çalışanlarının Ahlaki Duyarlılık Anketi puan ortalamalarının $83.0 \pm 16.3$ olduğu saptanmıştır. Yarar sağlama alt boyutunda 40 yaş üstü sağlık çalışanlarının diğer yaş grubundaki sağlık çalışanlarına göre etik duyarlılıkları yüksek bulunmuş ve istatistiksel açıdan ileri derecede anlamlı fark saptanmıştır ( $\mathrm{p}=0.001)$. Çatışma alt boyutunda evli sağlık çalışanlarının bekârlara göre; çocuk sahibi sağlık çalışanlarının çocuk sahibi olmayanlara göre etik duyarlılıkları yüksek bulunmuş ve istatistiksel açıdan anlamlı bir fark olduğu saptanmıştır $(\mathrm{p}<0.05)$. Sonuç: Hastane öncesi alanda ve hastane acil servislerinde çalışan sağlık çalışanlarının etik duyarlılıklarının yüksek olduğu saptanmıştır.

Anahtar Sözcükler: Acil, acil sağlık ekibi, acil servis, ahlaki duyarlılık ölçeği

\section{Determination of the ethical sensitivity of healthcare working in the pre-hospital area and hospital emergency service}

\begin{abstract}
Aim: This study is to identify ethical awareness and associated factors in emergency health teams. Methods: Target population of the study which is descriptive in nature is the emergency services of university and state hospitals located in Adana and health teams working in ambulance stations in Adana Local Health Authority. The data were collected through "Personal Identification Form" and "Moral Sensivity Questionnaire" developed by Lutzen.
\end{abstract}

Yazının geliş tarihi: 30.01 .2017

Yazının Kabul tarihi: 23.06.2017

Yazışma Adresi: Öğr. Gör. Secil Taylan, Çukurova Üniversitesi Sağlık Hizmetleri Meslek Yüksekokulu Balcali Kampüsü 01330 Sarıçam /Adana

Tel: 0530 3462062, E-posta: taylansecil@gmail.com 
Results: Results show that $68.7 \%$ of the emergency health personnel are female, $45.3 \%$ are married, $54.7 \%$ are single, $64.0 \%$ do not have children, $82.3 \%$ preferred this occupation themselves, $89.1 \%$ love their job, $79.8 \%$ have received ethics education, $86.6 \%$ do not follow any publications regarding ethics, and $71.4 \%$ do not have ethical committee in their institution. Moral Sensivity Questionnaire mean scores of health teams were found 83.0 \pm 16.3 . Benevolence sub-dimensional demonstrated statistically significant differences; moral sensivity mean scores of those over 40 were found to be significantly much higher than as compared to the other groups $(p=0.001)$. Experiencing Moral Conflict sub-dimensional so demonstrated statistically significant differences; ethical awareness of those who are married and who have children are found to be significantly higher than those who are single and who do not have children $(p<0.05)$. Conclusion: Emergency health teams' were found which indicates high moral sensivity

Keywords: Emergency, emergency health team, emergency service, moral sensivity questionnaire

\section{Giriş}

Acil bakım ilk anda uygulanacak tedavi ve bakımdır ve acil bakımın öncelikli amacı bireyin yaşamının kurtarılmasıdır. $\mathrm{Bu}$ sebeple acil bakımın en kisa zamanda uygulanması gerekir. ${ }^{1}$ Acil bakım sistemleri; hastane öncesi acil bakım ${ }^{2}$ ve hastane içi acil bakım ${ }^{3,4}$ olmak üzere iki alanda belirlenir. Hastane öncesi acil bakım hizmetlerinde mobil sağlık araçları olarak ambulanslar kullanılır.2,5 Teknolojideki hızlı ilerleme sağlık hizmetlerindeki tanı, tedavi ve bakım aşamalarını etkilemektedir. ${ }^{6}$ Acil sağlık ekip üyeleri, yapılacak müdahalelerin hayati önem taşıdığı acil hizmet birimlerinde fazla sorumluluk taşıma, aşırı stres yaşama ve birçok zaman hızlı karar verme gereği ile karşı karşıya gelmektedir.1,7-9 Karar verme sürecinde hastasının değerlerini ve beklentilerini karşlayan, en uygun tedavinin/bakımın uygulanmasına birey ile birlikte karar verilmesi önerilmektedir. ${ }^{10}$ Verilecek bakımın kalitesi, sağlık çalışanlarının etik duyarlılıklarının yüksek olması ile ilișkilidir. Etik duyarlılığın yüksek olması verilecek bakımın kalitesini etkiler. ${ }^{11}$

Literatürde bazı çalıșmalarda, etik duyarlılık ve ahlaki duyarlılık kavramlarına rastlanmaktadır.10-16 $\mathrm{Bu}$ iki kavram eş anlamlı gibi kullanılsa da; etik duyarlılık, etik kural ve ilkeleri bilme ile ilgili iken ahlaki duyarlılık daha çok kişiler arası ilişkileri bilme ile ilgilidir. Profesyonel davranışlar etik kodlar ile şekillenmektedir.16,17 Etik duyarlılık ahlaki duyarlılığın profesyonel boyutudur. $\mathrm{Bu}$ sebeple araștırmada "etik duyarlılık" kavramı kullanılmıştır.

"Etik bilgi" ve "etik davranış" kavramları arasındaki farkı kapatmak için ilk kez on yedinci yüzyılda İngiliz filozoflar tarafından "Etik duyarlılı" kavramından bahsedilmiștir. Felsefi bir kavram olan "etik duyarlılık" kavramı, ilk kez Anthony Ashley Cooper tarafından ahlaki anlamda tanıtılmış ve İngiliz filozof Shaftesbury, tarafından geliştirilmiştir. ${ }^{15}$

Sağlık çalışanları hizmet verdiği kişilerin yaşı, cinsiyeti, eğitimi, etnik kökeni, kültürü, manevi değerleri, dini inançları, kendi kararlarını alabilme yetileri, sözel ve sözel olmayan tüm davranışlarının farkında olmalı ve bu davranişları yorumlayabilmelidir.18,19 Aynı zamanda etik sorunlarla karşı karşıya kaldıklarında gerekli yasal ve etik sorumluluğu dikkate alabilecek, etik ikilemleri yönetecek ve kararlar alacak hastaları için en iyi olanı düşünerek onların haklarını savunacak, hastalarının kararlarına saygı gösterecek etik duyarlılığa sahip olmalıdırlar. ${ }^{19}$

Sağlık uygulamalarında etik, hasta bakımı ve tedavisinde doğabilecek etik sorunları tanımlamak, analiz etmek ve çözümlemek için sistematik bir yaklaşımı içermenin yanında kişiler arası düzeyde karar verme ile de ilgilidir. ${ }^{20}$ Sağlık çalışanlarının bakım ve tedavilerinden sorumlu oldukları kişilerin ihtiyaçlarını belirlemek, onları tanımak, onların 
davranışlarını yorumlamak, sorunlarını çözebilmek için bilişsel kapasitelerinin yeterli olması gerekir. Bu durum yüksek kaliteli bakımın ayrılmaz bir parçasıdır.17,21 Etik duyarlılık etik sorunları çözme, açıklık getirme ya da eylemi haklı çıkarma olarak düşünülmekle birlikte mutlak bir etik ikilemi ya da çatışmayı önlemektedir. ${ }^{22}$

Sağlık çalışanları etik ikilemler ile karşılaştığında, mesleki rolleri gereği evrensel etik değerler ve etik ilkeler rehberliğinde çözüm yolları üretme sorumluluğu taşır. ${ }^{13}$ Hızlı ve doğru karar vermenin hayati anlam taşıdığı acil sağlık ekibinin, yüksek etik duyarlılığa sahip olmaları gerekliliğinden hareketle araştırma, hastane öncesi alanda ve hastane acil servislerinde çalışan sağlık ekibinin etik duyarlılıklarını ve etkileyen faktörleri incelemek amacıyla yapılmıştır.

\section{Gereç ve Yöntem}

Araştırma, Adana ilinde hastane öncesi alanda ve hastane acil servislerinde çalışan sağlık ekibinin etik duyarlılıklarını belirlemek amacıyla tanımlayıcı nitelikte yapılmıştır. Araştırmayı yapabilmek için Çukurova Üniversitesi Girişimsel Olmayan Klinik Araştırmalar Etik Kurul'undan (Tarih: 9 Şubat 2012, Toplantı sayısı:5, Karar No:18) izni alınmıştır. Çalışmaya katılan sağlık çalışanlarından yazılı onam alınmıştır.

Araştırma, bir üniversite hastanesi, bir Eğitim ve Araștırma Hastanesi, iki Devlet Hastanesinin acil servislerinde ve Adana 112 İl Ambulans Servisi Başhekimliğine bağlı Ambulans İstasyonlarında görev yapan sağlık çalışanları ile Kasım 2011-Mart 2012 tarihleri arasında yürütülmüştür. Araştırmanın evrenini Adana il merkezindeki hastanelerin acil birimlerinde ve ambulans istasyonlarında görev yapan toplam 409 sağlık çalışanı oluşturmuştur. Araștırmada dișlanma kriteri belirlenmemiş, örneklem seçimine gidilmemiş ve evrenin tamamı örnekleme alınmıştır. Araştırmaya katılmayı kabul eden, araştırmanın yapıldığı tarihlerde izinli ve raporlu olmayan toplam 402 acil sağlık çalışanı araçtırma kapsamına alınmıştır.
Anket formu yüzyüze görüşme tekniği ile araştırmacı tarafından uygulamıştır.

Araştırma verileri "Bireysel Bilgi Formu" ve "Ahlaki Duyarlılık Anketi" kullanılarak elde edilmiştir. Araştırmada ölçek kullanıldığı için ön uygulama yapılmamıştır. Anket formunun ilk bölümünde "Bireysel Bilgi Formu" acil sağllk ekibinin meslek, cinsiyet, yaş, medeni durum, çocuk varlığı bireysel özelliklerine ait bilgiler, çalıştığı kurum ve birim, birimde çalışma süresi ve tercih durumu, etik eğitimi alıp almadığı, etik ile ilgili yayın takip etme durumu, çalıștığı kurumdaki etik kurul varlığına ait değişkenlerin yer aldığı toplam 14 sorudan oluşmuştur. Anket formunun ikinci bölümünde "Ahlaki Duyarlılık Anketi" (ADA) kullanılmıștır. ADA, Kim ${ }^{18}$ Lutzen $^{14}$ tarafından oluşturulmuş ve Karolinska Hemşirelik Enstitüsü'nde 1994 yılında ilk defa öncelikle psikiyatri kliniğinde sonra da diğer birimlerde çalıșan doktor ve hemșirelerde etik karar verme sürecinde gösterilen etik duyarlılığı belirlemek amacıyla kullanılmıştır. ADA ölçeğinin Türkçe geçerlilik ve güvenirliğini Tosun ${ }^{22}$ tarafından 2005 yılında yapılmıştır. Yapılan araștırmada ADA'nın Cronbach Alfa değeri 0.82 olarak bulunmuştur.

ADA toplam 30 madde ve 6 alt boyuttan oluşan likert türünde bir ölçüm aracıdır. Alt boyutlar; i. Otonomi $(10,12,15$, $16,21,24,27$. maddeler), ii. Yarar Sağlama $(2,5,8,25$. maddeler), iii. Bütüncül Yaklaşım $(1,6,18,29,30$. maddeler), iv. Çatışma $(9$, 11,14 . maddeler), v. Uygulama $(4,17,20$, 28. maddeler) ve vi. Oryantasyondan $(7,13$, 19, 22. maddeler) oluşmaktadır. 3, 23, ve 26. maddeler Lutzen'in yaptığı faktör analizi sonucunda herhangi bir alt boyutun kapsamında yer almamıştır. ${ }^{15,22}$.

ADA'da ifadeler bir puan (tamamen katılıyorum) ile yedi puan (hiç katılmiyorum) arasinda derecelendirilmiștir. Bu ifadelerde bir puan tamamen katılma yönünde yüksek duyarlılığı, yedi puan hiç katılmıyorum yönünde düşük duyarlılığı ifade etmektedir. ADA'dan alınabilecek en düşük puan 30 , en yüksek puan ise 210'dur. Düşük puan yüksek etik duyarlılığa, yüksek puan düşük etik duyarlılığa işaret eder. 
Verilerin değerlendirilmesinde SPSS 19.0 paket programı kullanılmıştır. Kategorik ölçümler sayı ve yüzde olarak, sayısal ölçümlerse ortalama ve standart sapma (gerekli yerlerde ortanca ve minimum-maksimum) olarak özetlenmiștir. Kategorik ölçümlerin gruplar arasında karşılaştırılmasında Ki-kare önemlilik testi kullanılmıştır. Cinsiyet, çocuk varlığı gibi ikili gruplar arasında sayısal ölçümlerin karşılaştırılmasında varsayımların sağlanması durumunda Bağımsız gruplarda $\mathrm{t}$ testi, varsayımların sağlanmaması durumunda ise Mann Whitney $U$ testi kullanılmıştır. Meslek, yaş grupları gibi ikiden fazla grubun sayısal ölçümlerinin genel karşılaştırılmasında varsayımların sağlanması durumunda Tek Yönlü Varyans Analizi, varsayımların sağlanmaması durumunda ise Kruskal Wallis testi kullanılmıştır. Bu karşılaştırmalarda anlamlı bulunan durumlar için grupların ikili alt grup karşılaştırılmalarında varsayımların sağlanması durumunda grup içi varyansların homojen olup olmamasina göre Scheffe, Tamhane testleri kullanılmıștır. Grupların ikili alt grup karşılaştırılmalarında varsayımların sağlanmaması durumunda ise Bonferroni düzeltmesi yapılarak Mann Whitney U testi kullanılmıştır. Tüm testlerde istatistiksel önem düzeyi 0.05 olarak alınmıștır.

\section{Bulgular}

Araştırmaya 81 (\%20.1) Hemşire, 52 (\%12.9) Doktor, 77 (\%19.2) İlk ve acil yardım teknikeri (Paramedik), 175 (\%43.5) Acil Tip Teknisyeni (Lise mezunu ambulansta ve acil servislerde çalışan sağlık çalışanı) ve 17 (\%4.3) Sağlık Memuru olmak üzere toplam 402 sağlık çalışanı katılmıştır (Tablo 1).

Acil sağllk ekibinin bireysel özelliklerinin dağılımı incelendiğinde, \%68.7'sinin kadın; \%78.6'sının 30 yaş altında; \%54.7'sinin bekâr; \%64.4'ünün çocuk sahibi olmadığı bulunmuştur. Acil sağlık ekibinin eğitim durumu incelendiğinde, \%46.3'ünün sağlık meslek lisesi, \%87.0'ının 10 yıl ve daha az süre ve \%54.0'ının hastanelerin acil servislerinde çalıştığı görülmüştür. Sağlık çalışanlarının \%82.3'ü görevlerinin kendi tercihi olduğunu, \%89.1'i görevlerini severek yaptıklarını belirtmişlerdir. Sağlık ekibinin tıp etiği eğitimi alma durumları incelendiğinde, \%79.8'i tıp etiği eğitimi aldığı, \%86.6'sının etik ile ilgili herhangi bir yayın takip etmediği, \%71.4'ünün çalıştığı kurumda etik kurul olmadığı saptanmıştır (Tablo 1).

Acil sağlık ekibinin ölçek puan ortalamaları incelendiğinde, otonomi boyutunda 18.6 \pm 6.8 , yarar sağlama boyutunda $15.7 \pm 4.6$, çatışma boyutunda $15.8 \pm 4.1$, uygulama boyutunda $10.7 \pm 4.0$, oryantasyon boyutunda $9.7 \pm 3.9$ olduğu, bütüncül yaklaşım boyutunda 12.5 \pm 5.6 olduğu, ADA'nın toplam puan ortalamasının ise $83.0 \pm 16.3$ olduğu saptanmıştır (Tablo 2).

Acil sağllk ekibinin cinsiyet, mesleğini tercih etme ve etik eğitimi alma durumlarının etik duyarlılıklarını etkilemediği belirlenmiștir $(p>0.05$, Tablo 1).

Mesleklerine göre etik duyarlılıkları arasındaki ilişki incelendiğinde ilk ve acil yardım teknikerlerinin otonomi, bütüncül yaklaşım, uygulama ve oryantasyon alt boyutlarında ve toplam puanda etik duyarlılıklarının yüksek olduğu, sağlık memurlarının ise yarar sağlama ve çatışma alt boyutlarında etik duyarlılıklarının yüksek olduğu belirlenmiştir $(\mathrm{p}<0.01$, Tablo 1).

30 yaş altındaki acil sağlık ekibinin otonomi, bütüncül yaklaşım, uygulama, oryantasyon alt boyutlarında (sirasiyla $\mathrm{p}$ değeri $0.001,0.021,<0.001,0.011$ ), 40 yaş üstü acil sağlık ekibinin ise yarar sağlama ve çatışma boyutlarında (sırasıyla p değeri $0.001,<0.001$ ) etik duyarlılıkları yüksek bulunmuştur (Tablo 1).

Acil sağlık ekibinin medeni durumlarına ve çocuk sahibi olma durumlarına göre tüm ADA ve alt boyutları puan ortalamalarının dağılımı incelendiğinde yalnızca çatışma alt boyut puan ortalamalarında istatistiksel açıdan anlamlı bir fark olduğu (sırasıyla $\mathrm{p}=0.026$, $\mathrm{p}=0.027$ ) bulunmuştur (Tablo 1). 
Lisansüstü mezunu olan acil sağlık ekibinin yarar sağlama ve çatışma alt boyutlarında etik duyarlılıklarının yüksek (sirasiyla $\mathrm{p}<0.001, \quad \mathrm{p}<0.001$ ); önlisans mezunu olan acil sağlık ekibinin otonomi, bütüncül yaklaşım, uygulama, oryantasyon alt boyutlarında etik duyarlılıklarının yüksek olduğu (sırasiyla $\mathrm{p}=0.001, \mathrm{p}=0.048$, $\mathrm{p}<0.001, \mathrm{p}=0.002$ ) belirlenmiştir (Tablo 1).

Mesleğini sevmeyerek yapan acil sağlık ekibinin yarar sağlama, bütüncül yaklaşım ve çatışma alt boyutlarında etik duyarlılıkları yüksek bulunmuştur (sırasıyla $\mathrm{p}<0.001, \mathrm{p}=0.017, \mathrm{p}<0.001$ ) (Tablo 1).

Acil sağlık ekibinin etik ile ilgili yayın takip etme durumlarına göre yarar sağlama ve çatışma alt boyut puan ortalamalarında istatistiksel açıdan anlamlı bir fark olduğu (sırasıyla $p=0.011, p=0.008$ ) bulunmuştur (Tablo 1) .

Çalıştığı kurumda etik kurul olduğunu bilen acil sağlı ekibinin yarar sağlama ve çatışma alt boyutlarında (sırasiyla $\mathrm{p}<0.001, \mathrm{p}<0.001$ ); bilmeyenlerin ise, otonomi, bütüncül yaklaşım, uygulama, oryantasyon alt boyutlarında etik duyarlılıklarının yüksek olduğu (sırasıyla $\mathrm{p}<0.001, \quad \mathrm{p}=0.034, \quad \mathrm{p}<0.001, \quad \mathrm{p}<0.001)$ bulunmuştur (Tablo 1).

\section{Tartışma}

$\mathrm{Bu}$ araştırmada hastane öncesi alanda ve hastanede çalışan acil sağlık çalışanlarının genç yaş grubunda olduğu ayrica oryantasyonda $(9.7 \pm 3.9)$ ve uygulamada $(10.7 \pm 4)$ etik duyarlılıklarının en yüksek olduğu bulunmuştur. Araştırmada sağlı çalışanlarının otonomilerinin düşük olduğu belirlenmiştir. Lutzen ve arkadaşlarının ${ }^{23} 2000$ yılında hemşireler ve doktorlar ile yapmış olduğu araștırmada otonomi alt boyutunda araştırmadan farklı olarak etik duyarlılığ yüksek bulunmuştur. Otonomi boyutunda etik duyarlılığın düşük olmasının sebebi, araştırma kapsamındaki sağlık çalışanlarının daha genç olmasından ve araştırmanın gerçekleştiği ilgili alanlarda acil bakım protokollerine bağlı olarak çalışılmasından kaynaklandığı düşünülmektedir.

$$
\text { Acil sağlı çalışanlarının }
$$
cinsiyetlerine göre ADA toplam puanı ile alt boyut puan ortalamaları arasinda istatistiksel farklılıkların olmadığı gözlenmiştir. Tosun ve arkadaşlarının araştırmasında ise kadın doktorlarda yaşanan çatışmanın erkek doktorlara göre daha fazla olduğu tespit edilmiştir. ${ }^{22}$ Lutzen ve arkadaşlarının ${ }^{18}$ araştırmasında ise oryantasyon alt boyutunda araștırma bulgumuza benzer şekilde cinsiyet faktörünün etik duyarlılığı etkilemediği bulunmuştur.

Araştırmaya katılan sağlık çalışanlarının yaş gruplarına göre otonomi alt boyutunda 30 yaş ve altı sağlık çalışanlarının etik duyarlılıkları yüksek $(p \leq 0.01)$ bulunmuş ve yaşın ilerlemesi ile otonominin azaldığı saptanmıştır. Lutzen ve arkadaşlarının ${ }^{20,23}$ her iki araştırmasında da yaş arttıkça otonomi düzeyi artarken, bizim araştırmamızda azaldığı saptanmıştır. İlerleyen yaş ile otonomi alt boyutunda duyarlılığının azalmasının, acil birimlerin oluşturdukları idari sistemden kaynaklandığı düşünülebilir. Yaş ve acil birimlerde çalışma süresi arttıkça idari sistemleri ve acil hastalıklara hızlı ve doğru müdahale etmeyi sağlamak için geliştirilen algoritmaları tanıma ve bilme düzeyi artmakta, bu durum sağlık çalışanlarının özerk davranmasındaki duyarlılığın azalmasına neden olabilmektedir.

Yarar sağlama alt boyutunda 30 yaş ve altı çalışanların etik duyarlılıklarının daha düşük $(\mathrm{p} \leq 0.01)$ bulunmuştur. Yaş ilerledikçe yarar sağlamanın arttığı tespit edilmiştir. Lutzen ve arkadaşlarının ${ }^{14} 2010$ yılında psikiyatri çalışanlarının ahlaki stres, ahlaki iklim ve ahlaki duyarlılıkları başlıklı çalışmalarında araştırma bulguları ile benzer olarak yaşın ilerlemesi ile yarar sağlamanın arttığı tespit etmişlerdir. Yaşın ilerlemesi ile mesleki bilgi ve becerinin artması ile yarar sağlamanın arttığı düşünülmektedir. 
Tablo 1. Acil Sağlık Ekibinin Tanımlayıcı Özelliklerine Göre ADA ve Alt Boyut Puan Ortalamalarının Dağılımı

\begin{tabular}{|c|c|c|c|c|c|c|c|c|c|c|}
\hline & Tanımlayıcı Özellikler & $\mathrm{n}$ & $\%$ & $\begin{array}{l}\text { Otonomi } \\
\text { x } \pm \text { sd } \\
\mathrm{p}\end{array}$ & 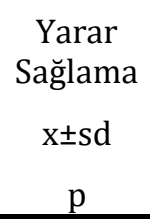 & 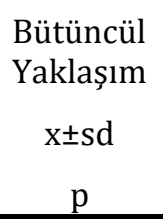 & 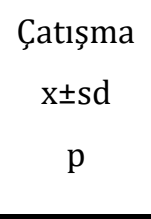 & $\begin{array}{l}\text { Uygulama } \\
\text { x } \pm \text { sd } \\
\text { p }\end{array}$ & $\begin{array}{c}\text { Oryantasyon } \\
\mathrm{X} \pm \mathrm{sd} \\
\mathrm{p}\end{array}$ & $\begin{array}{c}\text { Toplam } \\
\mathrm{x} \pm \mathrm{sd} \\
\mathrm{p}\end{array}$ \\
\hline \multirow{6}{*}{$\frac{\frac{y}{d}}{\frac{d}{d}}$} & Hemşire & 81 & 20.1 & $20.7 \pm 7.9$ & $14.2 \pm 4.9$ & $14.6 \pm 5.4$ & $13.7 \pm 3.2$ & $13.1 \pm 4.5$ & $11.3 \pm 5.4$ & $87.6 \pm 23.8$ \\
\hline & Doktor & 52 & 12.9 & $21 \pm 6.2$ & $13 \pm 4.6$ & $12.5 \pm 4.4$ & $13.2 \pm 3.6$ & $12.3 \pm 3.7$ & $9.9 \pm 4.1$ & $81.8 \pm 17$ \\
\hline & İlk ve Acil Y.Teknikeri & 77 & 19.2 & $16.3 \pm 5$ & $18.3 \pm 3$ & $10.6 \pm 2.6$ & $18.2 \pm 2.7$ & $9 \pm 2.5$ & $8.2 \pm 2.5$ & $80.6 \pm 9.4$ \\
\hline & Acil Tıp Teknisyeni & 175 & 43.5 & $17.7 \pm 6.5$ & $16.6 \pm 4.3$ & $12.2 \pm 6.7$ & $16.8 \pm 4.2$ & $9.8 \pm 3.6$ & $9.3 \pm 3.3$ & $82.5 \pm 13.6$ \\
\hline & Sağlık Memuru & 17 & 4.3 & $21.6 \pm 6.9$ & $11.7 \pm 4.2$ & $14.4 \pm 4.2$ & $11.9 \pm 3.2$ & $10.9 \pm 3.8$ & $11.5 \pm 3.6$ & $81.9 \pm 18.7$ \\
\hline & $\mathrm{p}$ & & & $<0.001$ & $<0.001$ & $<0.001$ & $<0.001$ & $<0.001$ & $<0.001$ & 0.071 \\
\hline \multirow{3}{*}{ 络 } & Erkek & 126 & 31,3 & $19.4 \pm 6.5$ & $15.7 \pm 4.8$ & $12.9 \pm 4.4$ & $15.5 \pm 4.3$ & $10.5 \pm 3.8$ & $9.8 \pm 4.2$ & $83.7 \pm 16.6$ \\
\hline & Kadın & 276 & 68,7 & $18.3 \pm 6.9$ & $15.8 \pm 4.5$ & $12.4 \pm 6.1$ & $15.9 \pm 4$ & $10.8 \pm 4.1$ & $9.6 \pm 3.8$ & $82.7 \pm 16.2$ \\
\hline & $\mathrm{p}$ & & & 0.144 & 0.831 & 0.415 & 0.379 & 0.551 & 0.598 & 0.562 \\
\hline \multirow{4}{*}{$\underset{\nu}{\pi}$} & $\leq 30$ & 316 & 78.6 & $18 \pm 6.3$ & $16.3 \pm 4.4$ & $12.2 \pm 5.6$ & $16.4 \pm 4$ & $10.2 \pm 3.7$ & $9.5 \pm 3.5$ & $82.6 \pm 13.8$ \\
\hline & $31-40$ & 62 & 15.4 & $20.2 \pm 6.3$ & $13.9 \pm 4.6$ & $13.2 \pm 4$ & $13.6 \pm 3.4$ & $12.3 \pm 3.9$ & $9.9 \pm 4.1$ & $83 \pm 15.6$ \\
\hline & $>40$ & 24 & 6.0 & $22.5 \pm 10.8$ & $13.3 \pm 6$ & $15.2 \pm 7.8$ & $12.9 \pm 3.8$ & $12.6 \pm 5.8$ & $12 \pm 7.2$ & $88.5 \pm 36.8$ \\
\hline & $\mathrm{p}$ & & & 0.001 & 0.001 & 0.021 & $<0.001$ & $<0.001$ & 0.011 & 0.232 \\
\hline
\end{tabular}


Tablo 1'in devamı

\begin{tabular}{|c|c|c|c|c|c|c|c|c|c|c|}
\hline & Tanımlayıcı Özellikler & $\mathrm{n}$ & $\%$ & $\begin{array}{l}\text { Otonomi } \\
\qquad \mathrm{x} \pm \mathrm{sd} \\
\mathrm{p}\end{array}$ & 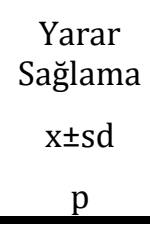 & 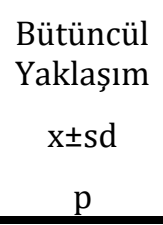 & $\begin{array}{c}\text { Çatışma } \\
\mathrm{x} \pm \text { sd } \\
\mathrm{p}\end{array}$ & $\begin{array}{c}\text { Uygulama } \\
\text { x } \pm s d \\
p\end{array}$ & 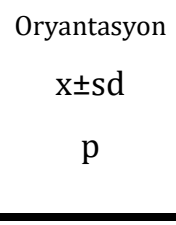 & $\begin{array}{c}\text { Toplam } \\
\text { x } \pm \text { sd } \\
\text { p }\end{array}$ \\
\hline \multirow{3}{*}{ 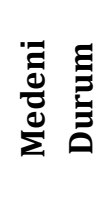 } & Evli & 182 & 45.3 & $18.5 \pm 7.2$ & $15.3 \pm 4.9$ & $12.1 \pm 4.6$ & $15.3 \pm 4.1$ & $10.8 \pm 4.2$ & $9.6 \pm 4.1$ & $81.7 \pm 18.3$ \\
\hline & Bekar & 220 & 54.7 & $18.8 \pm 6.4$ & $16.1 \pm 4.3$ & $12.8 \pm 6.3$ & $16.2 \pm 4.1$ & $10.6 \pm 3.8$ & $9.7 \pm 3.8$ & $84.2 \pm 14.5$ \\
\hline & $\mathrm{p}$ & & & 0.711 & 0.107 & 0.229 & 0.026 & 0.570 & 0.797 & 0.132 \\
\hline \multirow{3}{*}{ 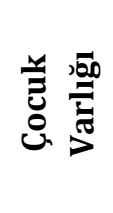 } & Hayır & 259 & 64.4 & $18.7 \pm 6$ & $16 \pm 4.4$ & $12.5 \pm 5.8$ & $16.1 \pm 4.2$ & $10.4 \pm 3.7$ & $9.6 \pm 3.6$ & $83.4 \pm 13.6$ \\
\hline & Evet & 143 & 35.6 & $18.5 \pm 7.9$ & $15.3 \pm 5$ & $12.5 \pm 5.2$ & $15.2 \pm 3.9$ & $11.1 \pm 4.4$ & $9.8 \pm 4.5$ & $82.4 \pm 20.4$ \\
\hline & $\mathrm{p}$ & & & 0.781 & 0.154 & 0.958 & 0.027 & 0.128 & 0.625 & 0.593 \\
\hline \multirow{5}{*}{ 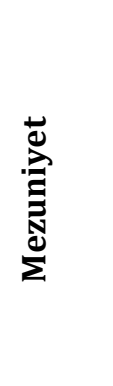 } & Lise & 186 & 46.3 & $18 \pm 6.6$ & $16.5 \pm 4.3$ & $12.4 \pm 6.6$ & $16.4 \pm 4.4$ & $10 \pm 3.6$ & $9.6 \pm 3.5$ & $82.9 \pm 13.8$ \\
\hline & Önlisans & 114 & 28.4 & $17.6 \pm 6.5$ & $16.6 \pm 4.4$ & $11.7 \pm 3.9$ & $16.7 \pm 3.5$ & $9.9 \pm 3.6$ & $8.8 \pm 3.7$ & $81.2 \pm 15.5$ \\
\hline & Lisans & 44 & 10.9 & $20.6 \pm 7.3$ & $13.9 \pm 4.7$ & $14.4 \pm 5.2$ & $14 \pm 3.2$ & $13.1 \pm 4.7$ & $10.9 \pm 4.3$ & $86.9 \pm 22.4$ \\
\hline & Lisansüstü & 58 & 14.4 & $21.2 \pm 6.6$ & $13.3 \pm 4.9$ & $13.1 \pm 4.8$ & $13.2 \pm 3.4$ & $12.5 \pm 3.9$ & $10.8 \pm 5$ & $84.1 \pm 19.7$ \\
\hline & $\mathrm{p}$ & & & 0.001 & $<0.001$ & 0.048 & $<0.001$ & $<0.001$ & 0.002 & 0.254 \\
\hline \multirow{3}{*}{ 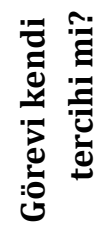 } & Evet & 331 & 82.3 & $18.6 \pm 6.7$ & $5.7 \pm 4.6$ & $12.5 \pm 5.8$ & $15.7 \pm 4.2$ & $10.7 \pm 3.8$ & $9.7 \pm 4$ & $82.9 \pm 15.8$ \\
\hline & Hayır & 71 & 17.7 & $18.9 \pm 7$ & $15.9 \pm 4.9$ & $12.5 \pm 4.9$ & $16.1 \pm 3.9$ & $10.8 \pm 4.5$ & $9.5 \pm 3.6$ & $83.6 \pm 18.5$ \\
\hline & & & & 0.753 & 0.801 & 0.999 & 0.475 & 0.829 & 0.636 & 0.751 \\
\hline
\end{tabular}


Tablo 1'in devamı

\begin{tabular}{|c|c|c|c|c|c|c|c|c|c|c|}
\hline & Tanımlayıcı Özellikler & $\mathrm{n}$ & $\%$ & $\begin{array}{l}\text { Otonomi } \\
\qquad \begin{array}{c}\mathrm{x} \pm \mathrm{sd} \\
\mathrm{p}\end{array}\end{array}$ & $\begin{array}{c}\text { Yarar } \\
\text { Sağlama } \\
\text { x } \pm \text { sd } \\
\text { p }\end{array}$ & 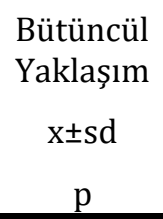 & 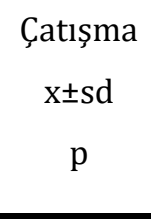 & $\begin{array}{c}\text { Uygulama } \\
\text { x } \pm \text { sd } \\
p\end{array}$ & $\begin{array}{c}\text { Oryantasyon } \\
\qquad \pm s d \\
p\end{array}$ & $\begin{array}{c}\text { Toplam } \\
\text { x } \pm \text { sd } \\
\text { p }\end{array}$ \\
\hline \multirow{3}{*}{ 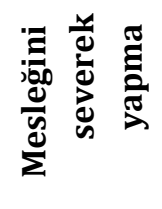 } & Evet & 358 & 89.1 & $8.5 \pm 6.8$ & $16.1 \pm 4.6$ & $12.3 \pm 5.7$ & $16.1 \pm 4$ & $10.6 \pm 4$ & $9.6 \pm 4$ & $83.1 \pm 16.2$ \\
\hline & Hayır & 44 & 10.5 & $19.6 \pm 6.7$ & $13.2 \pm 4.5$ & $14.4 \pm 4.4$ & $13.3 \pm 3.9$ & $11.6 \pm 3.9$ & $10.7 \pm 3.7$ & $82.9 \pm 17.6$ \\
\hline & $\mathrm{p}$ & & & 0.325 & $<0.001$ & 0.017 & $<0.001$ & 0.107 & 0.061 & 0.945 \\
\hline \multirow{3}{*}{ 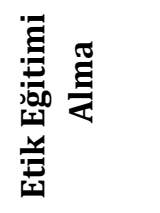 } & Evet & 321 & 79.8 & $18.7 \pm 6.4$ & $15.6 \pm 4.6$ & $12.4 \pm 5.8$ & $15.8 \pm 4.1$ & $10.6 \pm 3.9$ & $9.7 \pm 3.9$ & $82.8 \pm 15.9$ \\
\hline & Hayır & 81 & 20.2 & $18.5 \pm 8$ & $16.4 \pm 4.9$ & $12.9 \pm 4.8$ & $15.7 \pm 4.3$ & $10.9 \pm 4.1$ & $9.6 \pm 3.9$ & $84 \pm 18.1$ \\
\hline & $\mathrm{p}$ & & & 0.789 & 0.167 & 0.498 & 0.942 & 0.628 & 0.889 & 0.566 \\
\hline \multirow{3}{*}{ 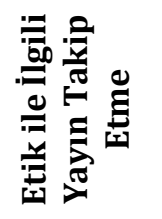 } & Evet & 54 & 13.4 & $19.7 \pm 6.9$ & $14.3 \pm 5$ & $12.6 \pm 4.7$ & $14.4 \pm 4$ & $11.2 \pm 4$ & $10.3 \pm 4.6$ & $82.4 \pm 17.4$ \\
\hline & Hayır & 348 & 86.6 & $18.5 \pm 6.7$ & $16 \pm 4.5$ & $12.5 \pm 5.7$ & $16 \pm 4.1$ & $10.6 \pm 4$ & $9.6 \pm 3.8$ & $83.1 \pm 16.2$ \\
\hline & $\mathrm{p}$ & & & 0.208 & 0.011 & 0.939 & 0.008 & 0.317 & 0.302 & 0.757 \\
\hline \multirow{3}{*}{ 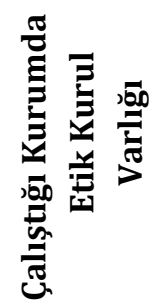 } & Evet & 115 & 28.6 & $20.9 \pm 7.4$ & $12.5 \pm 4.7$ & $13.5 \pm 5$ & $12.8 \pm 3.3$ & $12.6 \pm 4.2$ & $11.5 \pm 5.3$ & $83.7 \pm 21.7$ \\
\hline & Hayır & 287 & 71.4 & $17.7 \pm 6.3$ & $17.1 \pm 3.9$ & $12.1 \pm 5.8$ & $17 \pm 3.8$ & $9.9 \pm 3.6$ & $9 \pm 3$ & $82.8 \pm 13.6$ \\
\hline & $\mathrm{p}$ & & & $<0.001$ & $<0.001$ & 0.034 & $<0.001$ & $<0.001$ & $<0.001$ & 0.665 \\
\hline
\end{tabular}


Tablo 2. Acil sağlık ekibinin ADA ve alt boyut puan ortalamalarının dağılımı artması mesleki uygulamalarında daha fazla çatışma yaşamalarına neden olduğu düşünülebilir.

ADA'nın alt
boyut ve
toplam
potansiyel
puan dağılımı

Acil sağlık ekibinin ADA ve alt Boyut puan ortalamalarının dağılımı
Min-Max

Otonomi

Yarar

sağlama

Bütüncül

Yaklaşım

Çatışma

Uygulama

Oryantasyon

Total

$$
\text { 7-49 }
$$

4-28

5-35

3-21

$4-28$

4-28

$30-210$
Mean \pm Sd

$18.6 \pm 6.8$

$15.7 \pm 4.6$

$12.5 \pm 5.6$

$15.8 \pm 4.1$

$10.7 \pm 4.0$

$9.7 \pm 3.9$

$83 \pm 16.3$
Uygulama alt boyutunda 30 yaş ve altı çalışanların etik duyarlılıklarının daha yüksek olduğu $(p \leq 0.01)$ bulunmuştur. Genç yaştaki sağlık çalışanlarının etik duyarlılığının düşük olduğu fakat eyleme karar verme ve uygulamada ise etik duyarlılıklarının daha yüksek olduğu saptanmıştır. Çobanoğlu ve arkadaşlarının ${ }^{24}$ araştırmasında yoğun bakım ve acil hemşirelerinin iş yükünün fazla olması ve çalışma süresinin uzunluğu nedeni ile daha fazla duygusal tükenme ve duyarsızlaşma yaşadıkları saptanmış ve bu durumun problem çözme yeteneğini azalttı̆̆ belirtilmiştir. Acil sağlık çalışanlarının yaşla beraber uygulama alt boyutundaki düșmenin nedeninin yorgunluğun ve tükenmişliğin artması ile ilişkili olduğu düșünülmektedir.

Araştırmada sağlık çalışanlarının yaşın ilerlemesi ile otonomi, bütüncül yaklaşım, uygulama ve oryantasyon alt boyutunda etik duyarlılıklarının azaldığı, yarar sağlama ve çatışma alt boyutunda ise etik duyarlılıklarının arttığı belirlenmiştir. Leino-Kilpi ve arkadaşlarl $^{25}$ yaşla beraber etik duyarlılığın arttığını fakat Kim ve arkadaşları ${ }^{18}$ etik duyarlılığın yaşla beraber azaldığını belirtmişlerdir. Bu sonucun genç sağlık çalışanlarının klinik alanda daha aktif çalışması, daha ileri yaşlardaki sağlık çalışanlarının ise acil sistemin idari işleyişini daha iyi kavramalarından kaynaklandığı düşünülebilir.

Araştırmada medeni durum ve çocuk sahibi olmanın çatışma alt boyutu dışında etik duyarlılığı etkilemediği belirlenmiştir. Evli ve çocuk sahibi sağlık çalışanlarının, çatışma alt boyutunda etik duyarlılıkları yüksek $(\mathrm{p}<0.05)$ bulunmuştur. Lutzen ve arkadaşlarının araștırmasında ${ }^{20}$ araștırma bulgularına benzer șekilde medeni durum ile ADA arasında herhangi bir ilişki tespit edilmemiştir.

Otonomi alt boyutunda lisans ve lisansüstü mezunların etik duyarlılıklarının düşük olduğu $\quad(p=0.001)$ bulunmuştur. Eğitim derecesinin artması acil sağlı çalışanlarında özerk davranmayı negatif 
yönde etkileyerek idari sistemin getirdiği mesleki kuralları, standartları benimsemeyi ve profesyonel davranmayı pozitif etkilediği düşünülmektedir. Yarar sağlama alt boyutunda lisans ve lisansüstü mezunlarının benzer ve diğer çalışanların etik duyarlılıklarından daha yüksek olduğu belirlenmiştir. Bütüncül yaklaşım alt boyutunda önlisans mezunu çalışanların etik duyarlılıklarının en yüksek olduğu ve ileri istatistiksel analiz sonucunda çok ileri derecede anlamlı fark olduğu tespit edilmiştir $(\mathrm{p}<0.001)$. Bu sonucun ön lisans mezunlarının çoğunlukla ambulanslarda çalışmasından kaynaklandı̆̆ düşünülmektedir. Han ve arkadaşlarının ${ }^{26}$ ve Park ve arkadaşlarının ${ }^{27}$ hemşirelik öğrencileri yaptığı her iki araştırmada da lisans öğrencilerinin bütüncül yaklaşım alt boyutunda etik duyarlılığı daha yüksek saptanmıştır. Çatışma alt boyutunda Lisans ve Lisansüstü mezunlarının benzer ve diğer çalışanların etik duyarlılıklarından yüksek $(\mathrm{p}<0.001)$, uygulama alt boyutunda etik duyarlılıklarının düşük $(\mathrm{p}<0.001)$ olduğu tespit edilmiştir. ADA'nın genelinde ise anlamlı fark olmadığı tespit edilmiştir. Lisans ve lisansüstü sağlık çalışanları hemşire ve doktor guruplarını temsil etmektedir. $\mathrm{Bu}$ meslek guruplarının otonomi ve uygulama alt boyutunda etik duyarlılığı düşük fakat yarar sağlama ve çatışma alt boyutlarında etik duyarlılık yüksek bulunmuştur. Eğitim derecesinin artmasının yararlılığı arttırdığı ve eğitim derecesi yüksek kişilerin meslek gereklerini yerine getirirken daha fazla çatışma yaşadığı görülmektedir. Eğitim derecesinin artmasının özerk davranışlarında etik duyarlılığı azalttığı düşünülebilir.

Yarar sağlama ve çatışma alt boyutlarında çalışma süresi 10 yıl ve altında olan sağlık çalışanlarının en düşük etik duyarlılığa sahip olduğu $(p<0.001)$ tespit edilmiştir. Araştırmada Tosun'un ${ }^{22}$ araştırma sonuçlarına paralel olarak doktor ve hemşirelerde meslekte çalışma süresi arttıkça yarar sağlama alt boyutunda duyarlılığın arttığı bulunmuştur. Lutzen ve arkadaşlarının $^{15}$ psikiyatri ekibi ile yaptıkları araştırmada çalışma süresi arttıkça etik duyarlılığın arttığı tespit edilmiştir. Aynı araştırmada yaş ve çalışma yılı arttıkça meslektaşları ve yöneticileri tarafindan daha fazla desteklendikleri ve işi bırakmayı daha az düşündükleri, etik ikilemleri ve stresi daha az yaşadıkları ve yapmış oldukları meslekten memnuniyetin arttığ 1 bulunmuştur. ${ }^{15}$ Lutzen ve arkadaşlarının $^{21} 2003$ yılında yaptıkları araştırmada stres düzeyi arttıkça etik duyarlılığın azaldığına dikkat çekilmektedir.

Acil sağlık çalışanlarının çalıştıkları yere göre ADA ve alt boyut puan ortalamalarına bakıldığında hastane öncesi alanda çalışanların yarar sağlama ve çatışma alt boyutlarında etik duyarlılıklarının en düşük fakat uygulama alt boyutunda etik duyarlılıklarının en yüksek $(\mathrm{p}<0.001)$ olduğu belirlenmiştir. Genel olarak uygulama alt boyutunda etik duyarlılığın yüksek olması otonomi alt boyutunda etik duyarlılığ arttırdığı fakat çatışma ve yarar sağlama etik duyarlılığında azalmaya sebep olduğu söylenebilir.

Araştırmada mevcut görevinde çalışma süresi 10 yıl ve altında olan sağlık çalışanlarının, otonomi ve oryantasyon etik duyarlılıklarının daha yüksek $(\mathrm{p}<0.05)$ çatışma alt boyut duyarlılıklarının ise daha düşük $(\mathrm{p}<0.001)$ tespit edilmiştir. Jameton ${ }^{28}$ araştırmasında etik ikilemlerde hemşirelerin çoğunun yapması gerekeni bildiği halde zaman kısıtlılığı aciliyet durumlarında etik açıdan doğru kararları almada ikilemler yaşadığını bulmuştur. Lutzen ve arkadaşlarının ${ }^{21}$ araştırmasında deneyimi fazla kişilerin etik ikilemler karşısında en iyi olana karar vermede etik duyarlılığının daha yüksek olduğunu tespit etmişlerdir.

Yarar sağlama ve çatışma alt boyutunda mesleğini seven çalışanlarda etik duyarlılığın daha düşük $(\mathrm{p}<0.001)$ bütüncül yaklaşım alt boyutunda daha yüksek $(p<0.05)$ olduğu tespit edilmiştir. Mesleğini severek yapan sağlık çalışanlarının meslekten beklentilerinin fazla olması nedeni ile daha fazla çatışma yaşadıkları ve yarar sağlamanın azaldığı düşünülebilir. Bizim araştırmamızda Tosun'un ${ }^{22}$ araştırmasına benzer sonuçlara ulaşılarak mesleğini severek yapan doktor ve hemşirelerin bütüncül yaklaşımda daha başarılı oldukları $(\mathrm{p}<0.001)$ bulunmuştur. 
Araştırmadaki sağlık çalıșanlarının deontoloji/tıp etiği eğitimi alma durumuna göre ADA alt boyutları puan ortalamalarında istatistiksel farklılıkların olmadığı gözlenmiștir. $\mathrm{Bu}$ sonucun etik eğitiminin genel bilgi içeren teorik konular ağırlıklı olmasından kaynaklandığı düşünülmektedir. Comrie ${ }^{29}$ etik eğitimlerinde vaka ve simülasyon araştırmalarına yer verilmesinin sağlık çalışanlarının mesleki uygulamalarında etik ikilemlere karşı farkındalığı ve duyarlılığı arttıracağını ve böylece büyük etik ikilemler konusunda bilgi edinme ve çözüm yolları bulma firsatı verilerek bu tür eğitim faaliyetleri ile etik duyarlılık geliştirilmesinin sağlanabileceğini belirtmiştir. Kim ve arkadaşları ${ }^{18}$ etik eğitimi alan hemşirelerin etik duyarlılıklarının daha yüksek olduğunu saptamıştır. Weawer ${ }^{17}$ tüm sağlık çalışanlarının etik açıdan duyarlı bir ortamda çalışmaya ihtiyacı olduğunu belirtmektedir. Weawer ve arkadaşlarının ${ }^{16}$ başka bir araştırmasında sağlık çalışanı ile tedavi ve bakımını yürüttüğü hasta/sağlıklı bireylerin ilişkilerinin bu duyarlı ortamda yürütülmesi için idari destek alınmasının öneminden bahsedilmiştir. Aynı zamanda her iki araştırmada da eğitimlerle etik duyarlılığın geliştirilmesinin gerekliliği vurgulanmaktadır. ${ }^{16,17}$

Araştırmadaki sağlık çalışanlarının etikle ilgili yayın takip eden sağlık çalışanlarının yarar sağlama ve çatışma alt boyutları etik duyarlılıklarının daha yüksek olduğu saptanmıştır. Tosun ${ }^{22}$ araştırmasında ADA puan ortalamalarına göre; etik ile ilgili yayın izleyen doktorlarda yarar sağlama boyutunda etik duyarlılığın yüksek olduğunu $\quad(p<0.05)$ belirtmiştir. Çalıştı̆̆ kurumda etik kurul var olduğunu ifade eden acil sağlık çalışanlarının, otonomi, bütüncül yaklaşım, uygulama ve oryantasyon alt boyut etik duyarlılıklarının daha düşük olduğu fakat yarar sağlama ve çatışma alt boyut etik duyarlılıklarının daha yüksek olduğu gözlenmiştir. Tosun ${ }^{22}$ araştırmasında etik kurul bulunan kurumlarda çalışan doktorlarda ve hemşirelerde otonomi kullanma düzeyinin daha düşük olduğunu belirlemiştir. Aynı zamanda etik kurul bulunmayan kurumlardaki doktorlar da yarar sağlamanın daha yüksek düzeyde olduğunu; uygulama boyutu puan ortalamalarının daha iyi düzeyde olduğunu saptamıştır. Etik karar verme sürecinde, etkili olması gereken ve beklenen hastane etik kurullarının ülkemizde istenilen düzeyde işlevsel olmadığı, ağırlıklı olarak araştırma etiği üzerinde durulduğu bilinmektedir. Ayrıca ulaşılan literatür ve bilgilerde bu kurulların var olmasının gerekliliği üzerinde durulmaktadır. ${ }^{30-32}$ Ancak etik kurulların ne kadar etkili biçimde kullanıldığı üzerine yapılmış araștırmaya rastlanmamıștır.

Kim ve arkadaşları.18 araştırmasında çalıștıkları hastanelerde etik kurul olan hemşirelerin ahlaki duyarlılıklarının yüksek olduğunu tespit etmiştir.

\section{Sonuç}

Acil sağlık çalışanlarının etik duyarlılıklarının orta düzeyde olduğu, evli ve çocuk sahibi olanların daha fazla çatışma yaşadıkları belirlenmiştir.

Acil sağlık çalışanlarının yaş, mezun olduğu okul, çalıştığı yer, meslekteki ve mevcut görevlerindeki çalışma süreleri, mesleğini sevme, etik ile ilgili yayın takip etme ve çalıştığı kurumda etik kurul varlığı özelliklerinin ADA toplam puan ortalamasını etkilemediği fakat alt boyut puan ortalamalarını etkilediği saptanmıştır. $\mathrm{Bu}$ sonuçlar doğrultusunda acil sağlık çalışanlarının etik duyarlılığa ilişkin farkındalığın arttırılarak ve etik sorunları tanıma ve çözümünün sağlanabilmesi oldukça önemlidir.

\section{Kaynaklar}

1. Cowan RM, Trzeciak S. Clinical review: Emergency department overcrowding and the potential impact on the critically ill. Crit Care 2005;9:291-295.

2. Crill MT, Hostler D. Back strength and flexibility of EMS providers in practicing prehospital providers. $J$ Occup Rehabil 2005;15:105-111. 
3. Derlet RW. Overcrowding in emergency departments: effects on patients. Cal J Emerg Med 2000;1:2-3.

4. Lee FC, Chong WF, Chong P, Ooi SB. The emergency medicine department system: a study of the effects of computerization on the quality of medical records. Eur J Emerg Med 2001;8:107-115.

5. Sterud T, Ekeberg O, Hem E. Health status in the ambulance services: a systematic review. BMC Health Serv Res 2006;6:82.

6. Weiss SJ, Derlet R, Arndahl J et al. Estimating the degree of emergency department overcrowding in academic medical centers: results of the National ED Overcrowding Study (NEDOCS). Acad Emerg Med 2004;11:38-50.

7. Jonsson A, Segesten K, Mattsson B. Posttraumatic stress among Swedish ambulance personnel. Emerg Med J 2003;20:79-84.

8. van der Ploeg E, Dorresteijn SM, Kleber RJ. Critical incidents and chronic stressors at work: their impact on forensic doctors. J Occup Health Psychol 2003;8:157-166.

9. van der Ploeg E, Kleber RJ. Acute and chronic job stressors among ambulance personnel: predictors of health symptoms. Occup Environ Med 2003;60 (1):40-46.

10. Lutzen K. Time for ethics. Nurs Ethics 2008;15:145-146.

11. Lutzen K, Ewalds-Kvist B. Moral distress and its interconnection with moral sensitivity and moral resilience: viewed from the philosophy of Viktor E. Frankl.J Bioeth Inq 2013;10:317-324.

12. Ersoy N, Gundogmus UN. A study of the ethical sensitivity of physicians in Turkey. Nurs Ethics 2003;10:472-484.

13. Jeager S. Teaching Health Care Ethics: The İmportance of Moral Sensitivity for Moral Reasoning. Nursing Philosophy 2001;2: 31-42.

14. Lutzen K, Blom T, Ewalds-Kvist B, Winch S. Moral stress, moral climate and moral sensitivity among psychiatric professionals. Nurs Ethics 2010;17:213224.

15. Lutzen K, Dahlqvist V, Eriksson S, Norberg A. Developing the concept of moral sensitivity in health care practice. Nurs Ethics 2006;13:187-196.

16. Weaver K. Ethical sensitivity: state of knowledge and needs for further research. Nurs Ethics 2007;14:141-155.

17. Weaver K, Morse J, Mitcham C. Ethical sensitivity in professional practice: concept analysis. $J$ Adv Nurs 2008;62:607-618.

18. Kim YS, Park JW, You MA et al. Sensitivity to ethical issues confronted by Korean hospital staff nurses. Nurs Ethics 2005;12:595-605.

19. Schluter J, Winch S, Holzhauser K, Henderson A. Nurses' moral sensitivity and hospital ethical climate: a literature review. Nurs Ethics 2008;15:304-321.

20. Lutzen K, Evertzon M, Nordin C. Moral sensitivity in psychiatric practice. Nurs Ethics 1997;4:472-482.

21. Lutzen K, Cronqvist A, Magnusson A, Andersson L. Moral stress: synthesis of a concept. Nurs Ethics 2003;10:312-322.

22. Tosun H. Sağlık bakımı uygulmalarında deneyimlenen etik ikilemelere karşı hekim ve hemşirelerin duyarlılıklarının belirlenmesi(doktora tezi) Kamerya Babadağ Istanbul,2005.

23. Lutzen K, Johansson A, Nordstrom G. Moral sensitivity: some differences between nurses and physicians. Nurs Ethics 2000;7:520-530.

24. Cobanoglu N, Algier L. A qualitative analysis of ethical problems experienced by physicians and nurses in intensive care units in Turkey. Nurs Ethics 2004;11:444-458.

25. Leino-Kilpi H, Suominen T, Makela M et al. Organizational ethics in Finnish intensive care units: staff perceptions. Nurs Ethics 2002;9:126-136.

26. Han SS, Ahn SH. An analysis and evaluation of student nurses' 
participation in ethical decision making. Nurs Ethics 2000;7:113-123.

27. Park HA, Cameron ME, Han SS et al. Korean nursing students' ethical problems and ethical decision making. Nurs Ethics 2003;10:638-653.

28. Jameton A. Dilemmas of moral distress: moral responsibility and nursing practice. AWHONNS Clin Issues Perinat Womens Health Nurs 1993;4:542-551.
29. Comrie RW. An analysis of undergraduate and graduate student nurses' moral sensitivity. Nurs Ethics 2012;19:116-127.

30. Akan H. Etik kurullar. İyi Klinik Uygulamalar Dergisi 2001;1:3-6.

31. Tuncer M. Etik kurullar. İyi Klinik Uygulamalar Dergisi 2005;11:23-25.

32. İlbars $\mathrm{H}$, Yazgan $\mathrm{S}$, Dağıstanlı $\mathrm{S}$. Türkiye'de klinik ilaç araștırmaları. İyi Klinik Uygulamalar Dergisi 2003;7:3-12. 